\title{
Growth and reproductive performance of sambar deer in Sabal Forest Reserve of Sarawak, Malaysia
}

\begin{abstract}
We examined the growth, reproduction, rutting behavior, and health status of sambar deer (Cervus unicolor brookei) in secondary Acacia mangium plantation. The data were collected over 11 years from a breeding herd of 21 stags and 33 hinds in Sabal Forest Reserve, Sarawak, Malaysia. Brody's growth model of the pooled data is $\mathrm{Y} t=148.56$ $(1-0.98 \mathrm{e}-0.023 \mathrm{t})$, which estimates that maximum weights of adults are 184 and $115 \mathrm{~kg}$ for males and females respectively. Sambar deer are nonseasonal breeders with the breeding peak in February. Although the earliest age at which a female reached sexual maturity was 11 months, the mean age was $23 \pm 7$ months. Mean age of first fawning was $32 \pm 8$ months. Mean gestation period was $259 \pm 12$ days $(n=82)$. Stags shed antlers mostly between March and July. Velvet hardens at $103 \pm 27$ days $(n=23)$, and velvet harvesting is best at $7-9$ weeks when antler length is $25-30 \mathrm{~cm}$. Sambar deer are suitable as a farm species in forest plantations and have a vast potential to uplift rural living standards.
\end{abstract}

Keyword: Sambar deer; Growth; Reproductive performance; Rutting; Acacia mangium plantation 